\title{
The Effectiveness of Cochlear Implants in Patients with Inner Ear Malformation
}

\author{
Lina Alefranji ${ }^{1 *}$ and Khaled I Al-Noury ${ }^{2}$ \\ ${ }^{1}$ School of Advanced Education Research and Accreditation, Universidad Isabel I de Castilla, Spain \\ ${ }^{2}$ Department of Otolaryngology Head \& Neck Surgery, King Abdulaziz University, Saudi Arabia
}

Submission: February 1, 2021; Published: February 22, 2021

*Corresponding author: Lina Alefranji, School of Advanced Education Research and Accreditation • Universidad Isabel I de Castilla, Spain

\section{Abstract}

Purpose: To analyze the outcome of a cochlear implant (CI) in patients with an inner ear malformation (IEM), to compare two commonly used classification systems for IEM, to identify the highest and lowest outcome performance of IEM, to determine the most frequent inner ear anomalies and a candidate for a cochlear implant with considerable improvement.

Methods: A literature review including 64 previously published studies between the period 1987 to 2020 . In addition, a retrospective study inclusive 16 cases with IEM having undergone 20 CI surgeries.

Results: The review shows that 43 studies involving 1273 (19\%) cases with IEM out of 6560 patients have demonstrated an improvement in auditory and speech performance after implantation. 30 studies involving a total of 551 cases with an isolated enlarged vestibular aqueduct (EVA) have reported considerable benefits in audiology and speech performance after CI. Several authors reported that patients who have mild anomalies have a better outcome than patients who have severe malformations. Clinical studies revealed that patients with IEM have seen improvements in the outcome of audiology and speech tests after implantation.

Conclusion: $\mathrm{CI}$ is effective for patients who have severe to profound sensorineural hearing loss (SNHL) with inner ear anomalies despite other factors which may influence the outcome. The outcome of the minor IEM such as EVA is higher than the performance of the major anomalies like a common cavity (CC). The most frequent inner ear anomaly and candidate for the CI with significant improvement after implantation is EVA.

Keywords: Cochlear implant; Inner ear malformation; Enlarged vestibular aqueduct; Incomplete partition type I; Incomplete partition type II; Common cavity

\section{Abbreviations}

CI: Cochlear Implant, SNHL: Sensorineural Hearing Loss, IEM: Inner Ear Malformation, EVA: Enlarged Vestibular Aqueduct, IP I: incomplete partition type I, IP II: Incomplete Partition Type II, IP III: Incomplete Partition Type III, CC: Common Cavity, CLA: Complete Labyrinthine Aplasia, CH: Cochlear Hypoplasia ,CVM: Cochleovestibular Malformation, CSF: Cerebrospinal Fluid Leakage , PTA4: Average Pure Tone Audiometry of $(500 \mathrm{~Hz}, 1,2,4 \mathrm{KHz})$, FF: Free Filed, VRA: Visual Reinforcement Audiometry, SRT: Speech Recognition Threshold, SDS: Speech Discrimination Score, CAP-II: Categories of Auditory Performance II

\section{Introduction}

Cochlear implant (CI) is a surgical solution for patients who suffer from unilateral or bilateral severe to profound sensorineural hearing loss (SNHL) and is one of the most challenging ear surgeries as it needs a highly professional surgeon to perform it. This is especially the case for patients who have inner ear malformations (IEM), facial nerve abnormalities, cerebrospinal fluid leakage (CSF), gusher, or difficulty in finding the cochlea itself. Surgeons during the operation must be ready for any difficulties and then are required to modify the surgical approach or choose special electrodes according to the IEM. Several clinical studies have shown a significant improvement in auditory and speech perception performance after performing CI surgery for pediatric and adult patients who suffer from severe to profound SNHL in one ear or both sides of the ears. 


\section{Global Journal of Otolaryngology}

In 1791, an Italian physician and anatomist described the first inner ear malformation of an eight-year-old deaf boy. From that time "Mondini dysplasia" has been used to describe any inner ear anomalies [1]. Jackler et al. [2] was the first one to propose a classification of IEM based on embryonic arrested. Sennaroglu \& Saatci [3] have proposed a similar classification of IEM but with a distinction between incomplete partition type I (IP-I) and type II (IP-II). In 2015, Jeong \& Kim [4] introduced a new classification of cochleovestibular malformation (CVM) based on the morphology of the cochlea and the modiolus. In 2017, a new classification and management of IEM was proposed by Sennaroğlu \& Bajin [5]. In 1983, Mangabeira Albernaz reported the first CI for a patient with a malformed cochlea [6]. The most common classification that has been used to determine the IEM is Jackler et al. who classified the IEM into five categories and Sennaroğlu \& Bajin [5] who classified the inner ear anomalies into eight categories (Table 1).

Table 1: Classification of inner ear anomalies.

\begin{tabular}{|c|c|}
\hline Jackler Classifications (1987) & Sennaroğlu and Bajin Classifications (2017) \\
\hline $\begin{array}{l}\text { Complete labyrinthine aplasia (CLA) (Michel deformity): absent } \\
\text { of inner ear development }\end{array}$ & $\begin{array}{c}\text { Michel deformity is characterized by the absence of the cochlea, vestibule, SCCs, a } \\
\text { vestibular and cochlear aqueduct. }\end{array}$ \\
\hline $\begin{array}{l}\text { Cochlear aplasia: vestibule and semicircular canal might be } \\
\text { normal or malformed without cochlea }\end{array}$ & Cochlear aplasia: is a complete absent of cochlea with normal vestibule and SCCs. \\
\hline $\begin{array}{l}\text { Common cavity (CC): a common cavity between cochlea and } \\
\text { vestibule, the semicircular canal might be normal or mal- } \\
\text { formed. }\end{array}$ & $\begin{array}{l}\text { Common cavity: is characterized as a single, round, or avoid champers including } \\
\text { cochlea and vestibule. }\end{array}$ \\
\hline $\begin{array}{l}\text { Cochlear hypoplasia }(\mathrm{CH}) \text { : small cochlear bud, the semicircular } \\
\text { canal, and vestibule can be normal or malformed. }\end{array}$ & $\begin{array}{l}\text { Cochlear hypoplasia: is defined as a group of cochlear malformation, with abnor- } \\
\text { mal external dimensions. }\end{array}$ \\
\hline \multirow[t]{3}{*}{$\begin{array}{c}\text { Incomplete partition (IP): incomplete or small size of the } \\
\text { cochlea or no interscalar septum, vestibule, and SCC might be } \\
\text { normal or malformed. }\end{array}$} & $\begin{array}{l}\text { Incomplete partition of the cochlea: defined as a group of cochlear malformation } \\
\text { between cochlea and vestibule } \\
\text { a. Incomplete partition type I (IP I): the defect of the stapes footplate and oval } \\
\text { window } \\
\text { b. Incomplete partition type II (IP II): the apical part of the modiolus is affected. } \\
\text { c. Incomplete partition type IP III (IP III): a complete absence of the modiolus }\end{array}$ \\
\hline & $\begin{array}{l}\text { Rudimentary otocyst: is small otic capsule looks like a round or avoid shape, with } \\
\text { absent IAC. }\end{array}$ \\
\hline & $\begin{array}{c}\text { Enlarged vestibular aqueduct (EVA): the midpoint between the posterior } \\
\text { labyrinthine and operculum is equal or more than } 1.5 \mathrm{~mm} \text { with normal cochlea, } \\
\text { vestibule, and SCCs. }\end{array}$ \\
\hline- & $\begin{array}{l}\text { Cochlear aperture abnormalities: CA is hypoplastic when the width less than } 1.4 \\
\text { mm, and aplastic when there is no canal or replaced by bony. }\end{array}$ \\
\hline
\end{tabular}

\section{Materials and Methods}

This study was divided into two sections; the first consisting of a literature review which provides an analysis of previous studies. These studies were made up of scholarly journals and approaches (using database parameters such as PubMed, Google scholar, NCPI, Europe PMC, Academia, Balkan medical and SAGE Journals as well as using Research Gate to find articles in related fields. The collection of articles is from the period between 1987 till 2020. The second section was about a retrospective study: After the ethical approval of research committee of King Abdulaziz University Faculty of Medicine, and informed consent was signed from all participants, data were retrospectively compiled for this study consisting of thirty-two participants, including twenty-three children and nine adults who underwent forty CI surgeries at an average age of 3 years and 8 months in children, and 28 years and 4 months in adults (range between 2 to 50 years), sixteen patients were excluded from this study due to missing data in the postoperative aided hearing threshold and speech tests. The current study included sixteen patients, nine children and seven adults who have severe to profound SNHL with IEM. Out of twenty CI's in total, four patients with bilateral and twelve with unilateral hearing loss, were implanted with (MED-EL Innsbruck, Austria), between a period from 2012 to 2020 .

The inner ear anomalies were divided into: $(n=1)$ incomplete partition type I, ( $\mathrm{n}=12)$ incomplete partition type II (IP II), ( $\mathrm{n}=6)$ enlarged vestibular aqueduct (EVA), and $(n=1)$ common cavity (CC). The CI outcome has been evaluated by using a free filed (FF) test with adults and play audiometry or visual reinforcement audiometry (VRA) with children, In addition, the speech recognition test (SRT) and speech discrimination score (SDS) were evaluated by using the standardized Arabic speech materials lists and the patients were also evaluated with an Arabic version of categories of auditory performance II (CAP II), a computerized tomography (CT) scan and magnetic resonance imaging (MRI) was performed before the CI surgery to identify the type of inner ear anomalies. A postoperative CT scan was also performed to check the place of the inserted electrode inside the cochlea.

\section{Results}

\section{Literature review}

The first section of this study is analyzing the outcome of auditory and speech performance of previously published studies between 1987 until 2020 for patients who were diagnosed severe 
to profound sensorineural hearing loss, including IEM, and were implanted with a cochlear implant. The engine search showed a total of 799 related studies, out of which we found sixty-four studies that fulfill the inclusion criteria and are related to the outcome of a CI with IEM. The studies have included a total of 17636 CI subjects including 2836 (16\%) cases who were diagnosed with IEM with this being categorized into: ( $n=947)$ enlarged vestibular aqueduct at $33 \%,(n=153)$ common cavity at $5 \%,(n=135)$ cochlear hypoplasia at $5 \%,(n=102)$ incomplete partition "unclassified" at 4\%, $(n=156)$ incomplete partition type I at $6 \%$, $(\mathrm{n}=680)$ incomplete partition type II "Mondini" at $24 \%$, $(n=26)$ incomplete partition type III at $1 \%,(n=637)$ other malformations at $22 \%$ including single or multi malformations.

There are forty-three studies involving 1273 (19\%) cases with IEM out of 6560 patients who have demonstrated an improvement in auditory and speech performance after implantation. Thirty out of the 64 studies, involving a total of 551 cases with an isolated enlarged vestibular aqueduct, have reported considerable benefit in the audiology and speech performance after CI. In several studies, involving 2914 patients which included 419 inner ear malformation concluded that the outcome of patients with inner ear anomalies are like patients with the normal inner ear [7-22]. There are several studies which have compared the audiological outcome of patients with the control group being "normal inner ear anatomy", these studies having 391 patients as a result from the outcome of inner ear anomalies which is equal to the control group ( $\mathrm{n}=1436)$ [9-15,17,19-22].

Additionally, other studies reported a variable CI surgery outcome among patients based on types of inner ear anomalies [2,4,23-36]. Several authors reported that patients who have mild anomalies such as EVA and IP II have a better outcome than patients who have severe malformations such as a common cavity [4,24-28,31]. Nevertheless, Tay et al. has concluded that the outcome of patients who have an absent cochlear nerve, electrode folding and underlying neurological disorders is poor [37]. Xia et al. reported that twenty-one patients with a common cavity had benefited from a cochlear implant with the average performance being lower than patients with normal cochlea [38]. Three studies reported in a poor outcome after CI in patients who have a narrowing internal auditory canal $[4,34,37]$.

Busi et al. concluded that it is possible to get a good performance in the cochlear implant in children with ear or brain malformation abnormalities [39]. They also noticed the presence of central nervous system anomalies which can be an indication of a worse outcome. Aside from a negative expectation of common cavity and stenosis of an internal auditory canal for less than $2 \mathrm{~mm}$. Papsin concluded that care should be taken when opting for implanting patients with a narrow internal auditory canal [32]. Rachovitsas et al. concluded that children with inner ear malformation performed much better than patients with inner ear dysplastic because of their disabilities (such as CHARGE syndrome, and mental retardation). Bilingualism can also be considered as one of the factors that can affect the outcome of inner ear anomalies.

It is recommended to evaluate the cognitive and developmental delay before performing CI surgery and for counselling the parents about the expected outcome and habilitation [35]. Szudek et al. [40] reported a worse outcome from children and adults who were affecting by these factors; late of implantation, presence of gusher, and incomplete electrode insertion. Kim et al. [34] observed a poor cochlear implant outcome induced from cochlear nerve hypoplasia. Incesulu et al. had reported that they cannot accept CI surgery for inner ear anomalies except cochlear or cochleovestibular nerve agenesis due to cochlear implant contraindication [16]. Umashankar and Jayachandran have also shown a slow cochlear implant outcome of an individual with Goldenhar Syndrome associated with IEM [41].

\section{Case studies}

Table 2 shows the demographic data of the sixteen subjects who were diagnosed with severe to profound SNHL, the inner ear anomalies were divided into: $(n=1)$ incomplete partition type I, $(n=12)$ incomplete partition type II (IP II), ( $n=6)$ enlarged vestibular aqueduct (EVA), and $(n=1)$ common cavity (CC). There are twelve patients with unilateral CI (seven on the right side, and five on the left side), and four patients with a bilateral cochlear implant. All patients were implanted with MED-EL devices between 2012 until 2020. The types of the internal implant were distributed as follows; four of SONATAAti100, seven of CONCERTO, seven of SYNCHRONY and two of SYNCHRONY-P. It seems that most patients underwent CI surgery with a short electrode in size such as compressed, medium, form 24, Form 19, and Flex 24. The post CT scan demonstrated that fourteen CI had full insertion electrodes except three, due to fault in selecting the appropriate size of the electrode.

Table 2: Demographic data for adults and pediatric undergone $\mathrm{Cl}$ surgery.

\begin{tabular}{|c|c|c|c|c|c|c|c|c|}
\hline $\begin{array}{c}\text { Subject } \\
\text { no. }\end{array}$ & $\begin{array}{l}\text { Age at Im- } \\
\text { plantation }\end{array}$ & Side & Etiology & IEM & Implant Type & Electrode Type & $\begin{array}{l}\text { Speech } \\
\text { Processor }\end{array}$ & $\begin{array}{c}\text { Post-Radiology (Electrode } \\
\text { Insertion) }\end{array}$ \\
\hline \multicolumn{9}{|c|}{ Children } \\
\hline S1 R & 2 y $8 \mathrm{~m}$ & Right & Congenital & IP II & CONCERTO & FORM 24 & SONNET & Complete \\
\hline $\mathrm{L}$ & & Left & Congenital & IP II & CONCERTO & FORM 24 & SONNET & Complete \\
\hline S2 R & $5 y 8 \mathrm{~m}$ & Right & Congenital & IP II & CONCERTO & FLEX 24 & SONNET & 4 electrodes out \\
\hline
\end{tabular}


Global Journal of Otolaryngology

\begin{tabular}{|c|c|c|c|c|c|c|c|c|}
\hline $\mathrm{L}$ & & Left & Congenital & EVA & CONCERTO & FLEX 24 & OPUS 2 & 2 electrodes out \\
\hline S3 R & $4 \mathrm{y} 9 \mathrm{~m}$ & Right & Congenital & IP II & SYNCHRONY & FORM 24 & SONNET & Complete \\
\hline S4 L & $2 \mathrm{y} 2 \mathrm{~m}$ & Left & Congenital & IP II & SONATAti100 & Compressed & OPUS 2 & NM \\
\hline S5 R & 5 y $6 \mathrm{~m}$ & Right & Congenital & IP II & Mi12xx serious & Compressed & SONNET & NM \\
\hline S6 R & 4y $1 \mathrm{~m}$ & Right & Congenital & $\mathrm{CC}$ & SONATAti100 & Medium & RONDO & NM \\
\hline S7 L & $2 y$ & Left & Herdofamilial & IP II & SYNCHRONY & FLEX 28 & SONNET & Complete \\
\hline S8 R & $2 y$ & Right & Congenital & IP II & SYNCHRONY & FLEX28 & SONNET & Complete \\
\hline S9R & $5.5 y$ & Right & Herdofamilial & IP II & CONCERTO & FLEX28 & SONNET & Complete \\
\hline \multicolumn{9}{|c|}{ Adults } \\
\hline $\mathrm{S} 10 \mathrm{R}$ & $23 y$ & Right & Progressive & EVA & SYNCHRONY & FLEX 28 & RONDO & Complete \\
\hline $\mathrm{L}$ & & Left & Progressive & EVA & SYNCHRONY & FLEX 28 & RONDO & Complete \\
\hline S11 R & $25 \mathrm{y} 6 \mathrm{~m}$ & Right & Progressive & IP II & SYNCHRONY-P & FORM 24 & SONNET & Complete \\
\hline $\mathrm{L}$ & & Left & Progressive & IP II & SYNCHRONY-P & FORM24 & SONNET & Complete \\
\hline S12 L & $27 \mathrm{y} 2 \mathrm{~m}$ & Left & Progressive & EVA & SYNCHRONY & FORM 24 & SONNET & Complete \\
\hline S13 R & $20 y$ & Right & Congenital & IP II & CONCERTO & STANDARD & OPUS 2 & 2 electrodes out \\
\hline S14 R & $39 y$ & Right & Autoimmune & EVA & SONATAti100 & STANDARD & OPUS 2 & Complete \\
\hline S15 L & $50 y$ & Left & Unknown & EVA & SONATAti100 & STANDARD & OPUS 2 & Complete \\
\hline S16 L & $14 y$ & Left & Congenital & IP I & CONCERTO & FORM 19 & OPUS 2 & Complete \\
\hline
\end{tabular}

IEM: Inner Ear Malformation, EVA: Enlarged Vestibular Aqueduct, IP II: Incomplete Partition type II, CC: Common Cavity, IP I: Incomplete Partition Type I.

Table 3 shows that all the patients have a relative improvement in the post-implantation performance of aided hearing threshold and speech tests. Among the twenty CI surgeries, it has been seen that the average score of each frequency is between 31 to $36 \mathrm{~dB}$ (Figure 1), the progression of speech performance after CI surgery was high as the mean average of the SRT was 31 (Figure 2 ), the score of SDS was $72 \%$ (Figure 3) and all the participants reaching a CAP II score between 5 to 9 had an average score of 7 out of 9 (Figure 4) indicating that they can understand common phrases, converse with a familiar person without lip reading, use the telephone with a person they are familiar with, follow a conversation with a group in a noisy environment and are able to use the telephone with unknown people in an unpredictable context. There were four patients having had bilateral CI that benefited from their $\mathrm{CI}$ after implantation.

Table 3: Result of Post-Pure-Tone Audiometry Measurements and Speech Tests.

\begin{tabular}{|c|c|c|c|c|c|c|c|c|c|c|c|}
\hline \multirow{2}{*}{ Subjects } & \multirow{2}{*}{ Side } & \multicolumn{6}{|c|}{ Postoperative Pure-Tone Audiometry, dB } & \multicolumn{4}{|c|}{ Speech Tests } \\
\hline & & $250 \mathrm{HZ}$ & $500 \mathrm{HZ}$ & $1 \mathrm{KHZ}$ & $2 \mathrm{KHZ}$ & $4 \mathrm{KHZ}$ & $8 \mathrm{KHZ}$ & PTA4 & SRT & SDS & CAP-II \\
\hline \multirow{2}{*}{ S1 Bilateral } & Right & 30 & 35 & 40 & 35 & 30 & 30 & 35 & 35 & $80 \%$ & 8 \\
\hline & Left & 30 & 30 & 25 & 30 & 40 & 35 & 31 & 20 & $76 \%$ & 8 \\
\hline \multirow{2}{*}{ S2 Bilateral } & Right & 25 & 25 & 20 & 20 & 25 & 30 & 23 & 20 & $88 \%$ & 7 \\
\hline & Left & 35 & 30 & 25 & 20 & 30 & 40 & 26 & 25 & $80 \%$ & 7 \\
\hline S3 & Right & 25 & 20 & 20 & 20 & 20 & 25 & 20 & 15 & $88 \%$ & 7 \\
\hline S4 & Left & 25 & 30 & 30 & 30 & 40 & 30 & 33 & 35 & $64 \%$ & 6 \\
\hline S5 & Right & 30 & 25 & 35 & 25 & 25 & 30 & 28 & 30 & $52 \%$ & 5 \\
\hline S6 & Right & 40 & 40 & 40 & 40 & 45 & 45 & 41 & 45 & $52 \%$ & 5 \\
\hline S7 & Left & 30 & 35 & 30 & 30 & 35 & 30 & 32 & 35 & $70 \%$ & 5 \\
\hline S8 & Right & 35 & 35 & 30 & 35 & 30 & 35 & 33 & 25 & $90 \%$ & 7 \\
\hline S9 & Right & 35 & 35 & 40 & 30 & 35 & 40 & 36 & 30 & $70 \%$ & 6 \\
\hline \multirow{2}{*}{ S10 Bilateral } & Right & 30 & 20 & 20 & 35 & 30 & 35 & 26 & 35 & $80 \%$ & 6 \\
\hline & Left & 30 & 25 & 15 & 25 & 40 & 45 & 26 & 30 & $68 \%$ & 6 \\
\hline \multirow{2}{*}{ S11 Bilateral } & Right & 30 & 20 & 20 & 30 & 30 & 35 & 25 & 20 & $52 \%$ & 8 \\
\hline & Left & 25 & 25 & 25 & 30 & 30 & 45 & 28 & 25 & $56 \%$ & 5 \\
\hline
\end{tabular}


Global Journal of Otolaryngology

\begin{tabular}{|l|c|c|c|c|c|c|c|c|c|c|c|}
\hline S12 & Left & 55 & 55 & 45 & 55 & 55 & 60 & 53 & 50 & $76 \%$ & 6 \\
\hline S13 & Right & 35 & 30 & 30 & 30 & 30 & 30 & 31 & 30 & $70 \%$ & 7 \\
\hline S14 & Right & 25 & 30 & 30 & 35 & 35 & 35 & 32 & 35 & $90 \%$ & 9 \\
\hline S15 & Left & 40 & 30 & 40 & 35 & 30 & 30 & 34 & 40 & $70 \%$ & 8 \\
\hline S16 & Left & 40 & 35 & 35 & 30 & 30 & 35 & 34 & 35 & $60 \%$ & 7 \\
\hline
\end{tabular}

PTA4: Average Pure Tone Audiometry of $(500 \mathrm{~Hz}, 1,2,4 \mathrm{KHz})$, SRT: Speech Recognition Threshold, SDS: Speech Discrimination Score, CAP-II: Categories of Auditory Performance II.

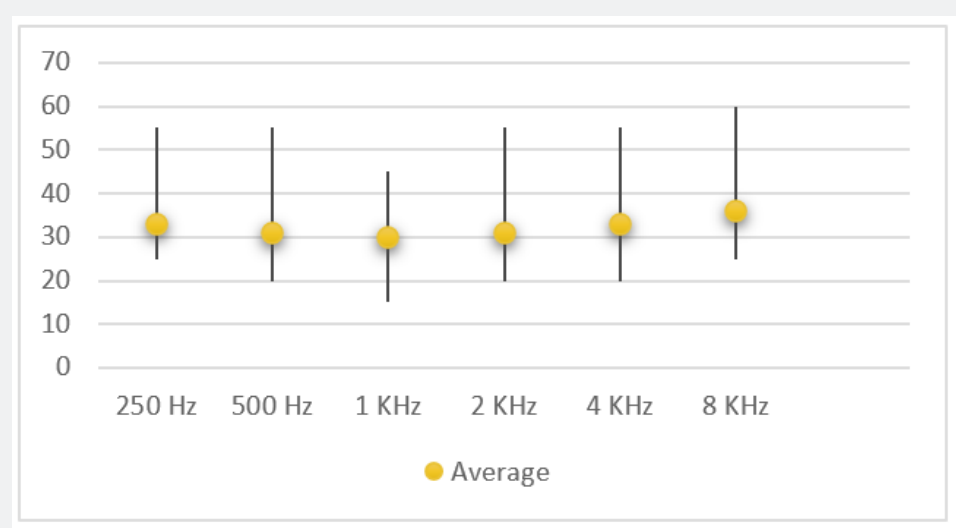

Figure 1: Post- Pure-tone audiometry.

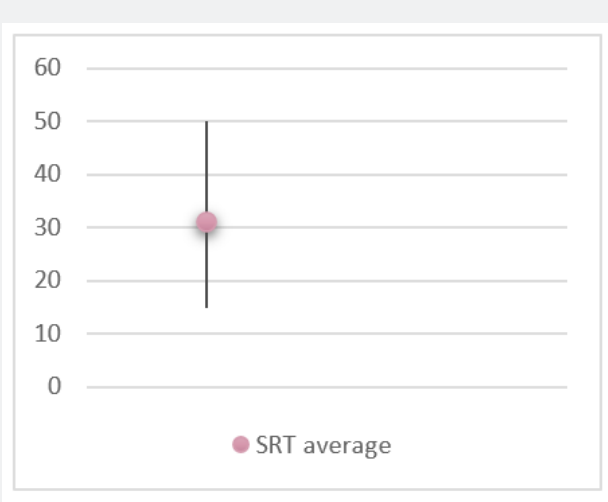

Figure 2: Speech recognition threshold.

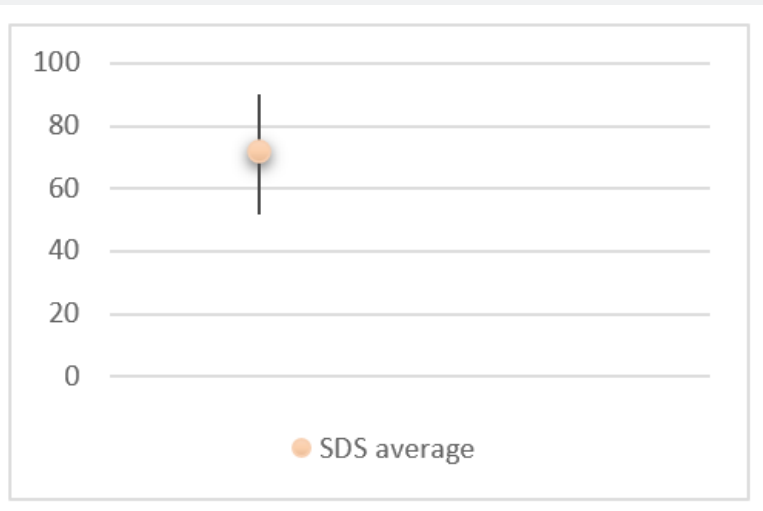

Figure 3: Speech discrimination score. 


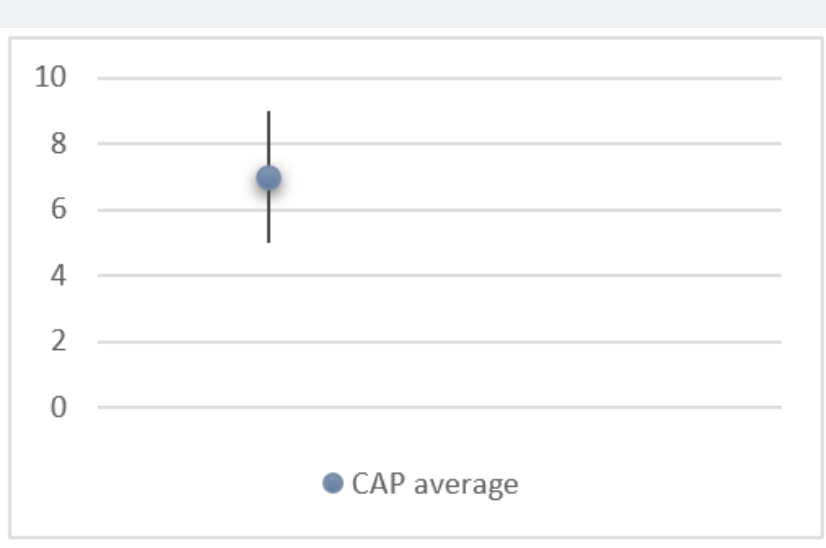

Figure 4: Categories of auditory performance.

Table 4 shows the average outcome of each anomaly, twenty cases having a good average at the aided hearing threshold and speech performance after performing CI. Six cases with enlarged vestibular aqueduct had a significant improvement in auditory and speech tests, twelve cases with incomplete partition type II had a good outcome after implantation, one patient with an incomplete partition type I and one patient with a common cavity showed an improvement but less than the average of EVA and IP type II. Among the twenty patients with IEMs, six patients with EVA achieved the highest performance scores with approximately $76 \%$ in the SDS and 8 in the CAP-II, twelve patients with IP II achieved $71 \%$ in the SDS and 7 in the CAP-II, one patient with IP I achieved $60 \%$ in the SDS and 6 in the CAP-II, and one patient with CC had the lowest scores with approximately $52 \%$ in the SDS and 5 in the CAP-II.

Table 4: The average outcome obtained from sixteen patients with twenty $\mathrm{Cl}$ surgeries.

\begin{tabular}{|c|c|c|c|c|c|c|c|c|c|c|c|}
\hline \multirow{2}{*}{ IEM } & \multicolumn{7}{|c|}{ Postoperative Pure-Tone Audiometry, dB } & \multicolumn{4}{|c|}{ Speech Tests } \\
\hline & (n) & $250 \mathrm{HZ}$ & $500 \mathrm{HZ}$ & $1 \mathrm{KHZ}$ & $2 \mathrm{KHZ}$ & $4 \mathrm{KHZ}$ & $8 \mathrm{KHZ}$ & PTA4 & SRT & SDS & CAP-II \\
\hline EVA & 6 & 38 & 33 & 26 & 34 & 39 & 45 & 33 & 35 & $76 \%$ & 8 \\
\hline IP II & 12 & 30 & 29 & 29 & 29 & 31 & 33 & 30 & 27 & $71 \%$ & 7 \\
\hline $\mathrm{CC}$ & 1 & 40 & 40 & 40 & 40 & 45 & 45 & 51 & 45 & $52 \%$ & 5 \\
\hline IP I & 1 & 40 & 35 & 35 & 30 & 30 & 35 & 34 & 35 & $60 \%$ & 6 \\
\hline
\end{tabular}

IEM: Inner Ear Malformation, PTA4: Average of Pure-Tone Audiometry, SRT: Speech Recognition Threshold, SDS: Speech Discrimination Score, CAP-II: Categories of Auditory Performance II, EVA: Enlarged Vestibular Aqueduct, IP II: Incomplete Partition Type II, CC: Common Cavity, IP I: Incomplete Partition Type I.

\section{Discussion}

A cochlear implant is a worldwide solution for patients who have severe to profound sensorineural hearing loss. This study has resulted in a considerable benefit in the aided hearing threshold and speech tests in children and adults with inner ear anomalies. This is especially in minor malformations like an enlarged vestibular aqueduct and incomplete partition type II. In addition, bilateral cochlear implantation for patients with IEM is effective. These results are in line with previously published works. Grover M. et al. had reported all subjects improved performance after cochlear implantation, especially patients with enlarged vestibular aqueduct [25]. Bille et al. [22] has studied 28 patients with incomplete partition type II and resulted that the outcome of patients with malformed cochlear is comparable to patients with normal cochlear anatomy. Qi et al. has studied 108 IEM with Mondini dysplasia out of 700 patients and concluded that the post-operative outcome of children with Mondini is equal to children with the radiological normal inner ear [14].

Arnoldner et al. concluded that the auditory response of speech for patients with IEM is like those in children with normal cochlea factoring in the success of implantation such as a preoperative radiological examination, a well-performed surgery, and an individually tailored postoperative rehabilitation program [18]. Van Wermeskerken et al. concluded that speech perception in children with inner ear anomalies is like that of other congenitally deaf children after an average of 2 years followup [19]. Chadha et al. stated that bilateral cochlear implantations with inner ear anomalies are effective and safe [42]. Pradhananga 
et al. has studied three cases with isolated EVA and concluded that a cochlear implant with a patient who has large vestibular aqueduct syndrome is effective and favorable [43].

Ozkan et al. reported that the outcome of cochlear implantation is acceptable in inner ear anomalies with patients with a visible cochlear nerve on magnetic resonance imaging. It is of fundamental importance to take the anatomical differences into account (especially after implantation during each visit), the rehabilitation sessions and to deal with each CI patient according to their needs [44]. The limitation of this study needs to be taken into account for any future research related to this topic: More research is required to evaluate the outcome of CI in patients with inner ear anomalies by using an Arabic standardized speech perception test in a different culture. It is also necessary to have a high number of patients with IEM with all types of anomalies, especially the minor and major inner ear malformation.

\section{Conclusion}

A cochlear implant is effective for children and adults who have severe to profound sensorineural hearing loss with inner ear malformations despite other factors which may influence the outcome. These can consist of the age at implantation, syndromes, pre- and post-lingual, duration of deafness, preoperative radiological examination, intraoperative challenging, the proper candidate electrode selection, postoperative complications, a well-performed surgery, an individually tailored postoperative rehabilitation program and family support. The outcome of the minor inner ear malformation such as EVA and IP-II is higher than the performance of the major anomalies like a common cavity. The most frequent inner ear anomaly and candidate for the $\mathrm{CI}$ with a considerable improvement after implantation is enlarged vestibular aqueduct.

\section{Acknowledgement}

We would like to thank Dr. Yassin Samad, Dr. Nithreen Said and Ms. Maram Al Kahtani for their generous help with data collection.

\section{References}

1. Al Shamsan L, Weir N, Palkar V, Hatlani M, Al Banyan E (2006) Diagnosis: Mondini dysplasia. Ann Saudi Med 26(2): 163-165.

2. Jackler RK, Luxford WM, House WF (1987) Congenital malformations of the inner ear: A classification based on embryo genesis. Laryngoscope 97(3): 2-14.

3. Sennaroglu L, Saatci I (2002) A New Classification for Cochleovestibular Malformations. Laryngoscope 112(12): 2230-2241.

4. Jeong SW, Kim LS (2015) A new classification of Cochleovestibular malformations and implications for predicting speech perception ability after cochlear implantation. Audiol Neurotol 20(2): 90-101.

5. Sennaroğlu L, Bajin MD (2017) Classification and current management of inner ear malformations. Balkan Med J 34(5): 397-411.

6. Mangabeira Albernaz PL (1983) The mondini dysplasia - from early diagnosis to cochlear implant. Acta Otolaryngol 95(5-6): 627-631.

7. Slattery WH, Luxford WM (1995) Cochlear implantation in the congenital malformed cochlea. Laryngoscope 105(11):1184-1187.

8. Luntz M, Balkany T, Hodges A V, Telischi FF (1997) Cochlear implants in children with congenital inner ear malformations. Arch Otolaryngol - Head Neck Surg 123(9): 974-977.

9. Manzoor NF, Wick CC, Wahba M, Gupta A, Piper R, et al. (2016) Bilateral Sequential cochlear implantation in patients with enlarged vestibular aqueduct (EVA) syndrome. Otol Neurotol 37(2): 96-103.

10. Melo AS, Martins J, Silva J, Quadros J, Paiva A (2017) Cochlear implantation in children with anomalous cochleovestibular anatomy. Auris Nasus Larynx 44(5): 509-516.

11. Sobhy O, Attallah M, Abdou R, Al Mahy A (2018) Assessment of cochlear implantation outcome in patients with enlarged vestibular aqueduct syndrome. Egypt J Otolaryngol 34(4): 316.

12. Sefein I, Younes A, Omara A, Hamada S, Sami A, et al. (2018) Outcome of cochlear implantation in children with enlarged vestibular aqueduct (EVA) and mondini dysplasia (incomplete partition type II). J Med Sci Res 1(1): 17.

13. Celik M, Karatas E, Kanlikama M (2018) Outcomes of cochlear implantation in children with and without inner ear malformations. Pakistan J Med Sci 34(2): 380-384.

14. Qi S, Kong Y, Xu T, Dong R, Lv J, Wang X, et al. (2019) Speech development in young children with Mondini dysplasia who had undergone cochlear implantation. Int J Pediatr Otorhinolaryngol 116: 118-124.

15. Eisenman DJ, Ashbaugh C, Zwolan TA, Arts HA, Telian SA (2001) Implantation of the malformed cochlea. Otol Neurotol 22(6): 834-841.

16. Incesulu A, Vural M, Erkam U, Kocaturk S (2002) Cochlear implantation in children with inner ear malformations: Report of two cases. Int J Pediatr Otorhinolaryngol 65(2): 171-179.

17. Miyamoto RT, Bichey BG, Wynne MK, Kirk KI (2002) Cochlear implantation with large vestibular aqueduct syndrome. Laryngoscope 112(71): 1178-1182.

18. Arnoldner C, Baumgartner WD, Gstoettner W, Egelierler B, Czerny C, et al. (2004) Audiological performance after cochlear implantation in children with inner ear malformations. Int J Pediatr Otorhinolaryngol 68(4): 457-467.

19. Van Wermeskerken GKA, Dunnebier EA, Van Olphen AF, Van Zanten BA, Albers FWJ (2007) Audiological performance after cochlear implantation: A 2-year follow-up in children with inner ear malformations. Acta Otolaryngo 127(3): 252-257.

20. Wan L cai, Guo M he, Qian Y hong, Liu S xiu, Zhang H zheng, et al. (2009) Cochlear implant in patients with congenital malformation of the inner ear. Nan Fang Yi Ke Da Xue Xue Bao 29(10): 2118-2121.

21. Aschendorff A, Laszig R, Maier W, Beck R, Schild C, Birkenhäger R, et al. (2009) Cochlear implant for malformations of the inner ear. HNO 57(6): 533-541.

22. Bille J, Fink Jensen V, Ovesen T (2015) Outcome of cochlear implantation in children with cochlear malformations. Eur Arch OtoRhino-Laryngology 272(3): 583-589.

23. Berrettini S, Forli F, De Vito A, Bruschini L, Quaranta N (2013) Cochlear implant in incomplete partition type I. Acta Otorhinolaryngol Ital 33(1): 56-62.

24. Isaiah A, Lee D, Lenes-Voit F, Sweeney M, Kutz W, Isaacson B, et al. (2017) Clinical outcomes following cochlear implantation in children with inner ear anomalies. Int J Pediatr Otorhinolaryngol 93: 1-6.

25. Grover M, Sharma S, Bhargava S, Singh SN, Gupta G, et al. (2017) Cochlear Implantation in Children with Anomalous Cochleovestibular Anatomy: Our Experience. Indian J Otolaryngol Head Neck Surg 69(4): 504-508. 
26. Shi Y, Li Y, Gong Y, Chen B, Chen J (2019) Cochlear implants for patients with inner ear malformation: Experience in a cohort of 877 surgeries. Clin Otolaryngol 44(4): 702-706.

27. Demir B, Cesur S, Sahin A, Binnetoglu A, Ciprut A, Batman C (2019) Outcomes of cochlear implantation in children with inner ear malformations. Eur Arch Oto-Rhino-Laryngology 276(9): 2397-2403.

28. Han JJ, Suh MW, Park MK, Koo JW, Lee JH, et al. (2019) A Predictive Model for Cochlear Implant Outcome in Children with Cochlear Nerve Deficiency. Sci Rep 9(1).

29. Weber BP, Dillo W, Dietrich B, Maneke I, Bertram B, Lenarz T (1998) Pediatric cochlear implantation in cochlear malformations. Am J Otol 19(6): 747-753.

30. Mylanus EAM, Rotteveel LJC, Leeuw RL (2004) Congenital malformation of the inner ear and pediatric cochlear implantation. Otol Neurotol 25(3): 308-317.

31. Buchman CA, Copeland BJ, Yu KK, Brown CJ, Carrasco VN, et al. (2004) Cochlear Implantation in Children with Congenital Inner Ear Malformations. Laryngoscope 114(2): 309-316.

32. Papsin BC (2005) Cochlear Implantation in Children with Anomalous Cochleovestibular Anatomy. Laryngoscope 115(S106): 1-26.

33. Ahmad RL, Lokman S, Raja AAK (2005) Cochlear implantation in congenital cochlear abnormalities. Med J Malaysia 60(3): 379-382.

34. Kim LS, Jeong SW, Huh MJ, Park YD (2006) Cochlear implantation in children with inner ear malformations. Ann Otol Rhinol Laryngol 115(3): 205-214.

35. Rachovitsas D, Psillas G, Chatzigiannakidou V, Triaridis S, Constantinidis J, et al. (2012) Speech perception and production in children with inner ear malformations after cochlear implantation. Int J Pediatr Otorhinolaryngol 76(9): 1370-1374.
36. Pakdaman MN, Herrmann BS, Curtin HD, Van Beek-King J, Lee DJ (2012) Cochlear implantation in children with anomalous cochleovestibular anatomy: A systematic review. Otolaryngol Head Neck Surg 146(2): 180-190.

37. Tay SY, Anicete R, Tan KKH (2019) A Ten-Year Review of Audiological Performance in Children with Inner Ear Abnormalities after Cochlear Implantation in Singapore. Int J Otolaryngol 2019: 1-8.

38. Xia J, Wang W, Zhang D (2015) Cochlear implantation in 21 patients with common cavity malformation. Acta Otolaryngol 135(5): 459-465.

39. Busi M, Rosignoli M, Castiglione A, Minazzi F, Trevisi P, Aimoni C, et al. (2015) Cochlear Implant Outcomes and Genetic Mutations in Children with Ear and Brain Anomalies. Biomed Res Int 2015: 696281.

40. Szudek J, Dettman S, Zraika L, Briggs R (2013) Cochlear Implant Outcomes in Adults and Children with Inner Ear Malformations. Otolaryngol Neck Surg 149(2_suppl): 219.

41. Umashankar A, Jayachandran D (2019) Measurement of Cochlear Implant Outcomes in Goldenhar Syndrome: A Case Report. Indian J Case Reports 5(5): 448-450.

42. Chadha NK, James AL, Gordon KA, Blaser S, Papsin BC (2009) Bilateral cochlear implantation in children with anomalous cochleovestibular anatomy. Arch Otolaryngol - Head Neck Surg 135(9): 903-909.

43. Pradhananga R, Natarajan K, Devarasetty AN, Kameswaran M (2014) Cochlear Implantation in Isolated Large Vestibular Aqueduct Syndrome: Report of Three Cases and Literature Review. Int Arch Otorhinolaryngol 19(4): 359-363.

44. Ozkan HB, Cicek Cinar B, Yucel E, Sennaroglu G, Sennaroglu L (2020) Audiological Performance in Children with Inner Ear Malformations Before and After Cochlear Implantation: A Cohort Study of 274 Patients. Clin Otolaryngol 0: 1-7.

\section{Your next submission with Juniper Publishers will reach you the below assets}

- Quality Editorial service

- Swift Peer Review

- Reprints availability

- E-prints Service

- Manuscript Podcast for convenient understanding

- Global attainment for your research

- Manuscript accessibility in different formats

( Pdf, E-pub, Full Text, Audio)

- Unceasing customer service

Track the below URL for one-step submission https://juniperpublishers.com/online-submission.php 